\title{
Boredom in Borderline Personality Disorder: A Lost Criterion Reconsidered
}

\author{
Sara R. Masland ${ }^{\mathrm{a}}$ Tanya V. Shah $^{\mathrm{a}}$ Lois W. Choi-Kain ${ }^{\mathrm{b}}$ \\ ${ }^{a}$ Psychological Science, Pomona College, Claremont, CA, USA; ${ }^{b}$ McLean Hospital, Harvard Medical School, Belmont, \\ MA, USA
}

\section{Keywords}

Borderline personality disorder - Boredom - Emptiness ·

Diagnostic criteria $\cdot$ Personality disorders

\begin{abstract}
Difficulty with boredom was eliminated from the formal diagnostic criteria for borderline personality disorder (BPD) in 1994 based on significantly limited, unpublished data. However, it is apparent in clinical practice that boredom remains relevant to BPD. This review synthesizes empirical research, with consideration of theoretical accounts, to critically examine the relevance of boredom to BPD. We first briefly review issues in defining and measuring boredom and offer an expanded conceptualization for BPD, which includes the notion of boredom reactivity, before turning to boredom's differentiation from and overlap with feelings of emptiness, with which it was paired prior to its removal from the DSM. We then discuss perspectives on boredom's significance in $B P D$, briefly touching on its relevance in other personality disorders. We propose a Boredom Cascade Model that articulates how boredom and boredom reactivity interact with identity disturbance and chronic emptiness to create escalating patterns of behavioral dysregulation and make recommendations for research and treatment.
\end{abstract}

(c) 2020 S. Karger AG, Basel

\section{Introduction}

When borderline personality disorder (BPD) was first formalized in the diagnostic nomenclature in the DSMIII [1], initial criteria included "chronic feelings of emptiness or boredom" (p. 347). The DSM Task Force later amended this criterion in the DSM-IV [2] to exclude boredom. This change persists in the current DSM-5, where the criterion now simply reads, "chronic feelings of emptiness" [3, p. 663]. The primary motivation for this change was that chronic boredom was "not particularly useful" in making the diagnosis [4, p. 346], a conclusion based on opinions from users of the Diagnostic Interview for Borderlines (DIB) and an unpublished analysis, which Gunderson et al. [4] cite as a "personal communication." These unpublished data suggested that emptiness better discriminated BPD from other personality disorders than boredom. This was confirmed in 1 published study, in which mean levels of boredom (and emptiness, measured separately) were slightly, but not statistically, higher for a small sample of people with BPD relative to those with narcissistic personality disorder [5].

Later, others noted that boredom was removed because "chronic feelings of boredom will be more characteristic of the antisocial, narcissistic, and schizoid personality disorders," emptiness may better indicate issues with 
identity diffusion than boredom, and "boredom can trivialize the severity of the pathology" [6, p. 98]. However, the assertion that boredom is more characteristic of other personality disorders was based largely on theoretical, rather than empirical evidence, as was the assertion that emptiness may be more strongly linked to identity disturbance than boredom [e.g., 7]. The evidence suggesting that boredom is non-discriminating for BPD is surprisingly limited in scope and availability given its influence on a major diagnostic change. And although the revised criterion may have "moderate usefulness" [8, p. 259], it ranks lowest for diagnostic efficiency [9] and item-total correlation $[8,9]$ among the BPD criteria. In other words, the "chronic emptiness" criterion suffers from poor discriminant and convergent validity.

Notably, the observation that borderline patients are "easily bored...[and] may constantly seek something to do" [2, p. 707; 3, p. 664] persisted in the DSM-IV and DSM-5, but was relegated to the general description of $\mathrm{BPD}$. This is consistent with the notion that boredom remains a clinically relevant and important aspect of BPD, deserving of further study. Studies in non-clinical samples show that boredom proneness is associated with many features of BPD, including impulsivity $[10,11]$; aggression, anger, and hostility [12]; interpersonal sensitivity [13]; and interpersonal difficulties $[14,15]$. These associations are supported by clinical and theoretical accounts of BPD which describe both a chronic, pervasive tendency toward boredom and an inability to tolerate it. Problems with boredom may also contribute to maladaptive behavioral patterns in BPD.

The aim of this paper is to critically examine the relevance of boredom to BPD. We first briefly review issues in defining and measuring boredom, before turning to its differentiation from and overlap with feelings of emptiness. We then discuss perspectives on boredom's significance in BPD, briefly touching on its relevance in other personality disorders, before proposing a Boredom Cascade Model. We end with a call for research on the importance of boredom in BPD, suggest specific areas for inquiry, and offer insights for treatment.

\section{Boredom}

Historically, there has been significant disagreement about how to define boredom [16], and difficulties defining boredom and distinguishing it from related states likely contributed to its elimination from the diagnostic criteria for BPD. However, there are common threads across modern definitions of boredom. For example, Fahlman et al. [17] argue that "all theories suggest that the central defining feature of boredom is the aversive experience of wanting, but being unable, to engage in stimulating and satisfying activity" (p. 69). Similarly, Westgate and Wilson [18] position boredom as "an affective indicator of unsuccessful engagement in valued goal-congruent activity" (p. 1). A state-trait account of boredom disentangles the momentary experience of boredom from the general propensity to feel bored, while a circumplex model of emotion [e.g., 19], in which affect is understood in terms of underlying dimensions of valence (i.e., pleasantness-unpleasantness) and arousal (i.e., high-low activation) is useful for understanding the state experience.

\section{State and Trait Boredom}

Like other affects, boredom may also be understood in terms of state (momentary) and trait-like (dispositional) forms. Although any individual may experience state boredom, those high on trait boredom are more likely to experience boredom or to experience it more frequently. State boredom is momentary and somewhat ephemeral [20], while trait boredom is considered akin to a personality characteristic, generally pervasive and present across contexts [21]. Trait boredom, often referred to as boredom proneness, can be regarded as a chronic propensity to experience state boredom or to label experiences as boring [22]. The majority of boredom research focuses on trait boredom, or boredom proneness, and has highlighted its associations with low levels of persistence and poor impulse control, rigid cognitive style [10]; difficulties with self-control or regulating engagement [23]; preference for low-effort activities [24]; low absorption and low self-awareness [25]; neuroticism and poor emotional adjustment $[26,27]$; preoccupation with mood combined with a poor capacity for mood labelling [28]; high optimal level of arousal [29]; alexithymia [30, 31]; and dysregulated attention [17, 31-33].

\section{Valence and Arousal}

In terms of valence, boredom is largely regarded as a negative or unpleasant experience: approximately $55 \%$ of boredom definitions note its unpleasant nature [19]. The arousal dimension of boredom is less clear. Most prominent theories suggest that boredom is a low-arousal state. This has been described directly as "low arousal" [e.g., 17, 34], as a "deactivated state that is manifested in emotions such as weariness and lethargy" [20, p. 479], or "apathetic" [33]. In circumplex models, boredom is considered a deactivated/unpleasant state [35-37], distinct from other 
low-arousal states, including apathy, anhedonia, and depression [38]. It has been described as the space between misery and sleepiness $[39,40]$. Notably, what is perceived as low arousal may vary based on an individual's optimal or desired level of arousal [41-44].

Others have argued that boredom may also involve high arousal [e.g., 17], or a restless or agitated state in which one fails to find satisfactory engagement with the environment despite motivation to do so $[33,45]$. However, this agitated high arousal may not be boredom itself, but rather a psychological state of frustration that results from the negative experience of low arousal [37]. In other words, high arousal may result from a tendency to feel distressed upon experiencing boredom and attempts to escape that distress [20]. As Westgate and Wilson [18] state, "whereas boredom is about the process, frustration is about the outcome of that process" (p. 6).

\section{Measuring Boredom}

Existing self-report measures of boredom tend to conflate the general description or experience of boredom with its causes and consequences [46]. They also tend to focus on specific features of the experience or particular contexts, including work $[47,48]$, leisure time $[49,50]$, or interpersonal relationships [51]. An obvious limitation of these measures is their restricted scope, and their clinical utility is difficult to establish [16]. All available self-report measures of boredom were developed in non-clinical populations, consistent with the predominant non-clinical research focus in the boredom literature. It is unclear whether we may expect similar manifestations of boredom, or similar relations among boredom and other constructs, in psychiatric samples. We return to these limitations when we present recommendations. Moreover, although their item content is not obviously conflated with emptiness, the extent to which these measures also tap emptiness is unclear. Vodanovich and Watt [46] provide a comprehensive review of specific measures, with one important exception, published more recently: the State Boredom Inventory (SBI) [20]. To date, the Multidimensional State Boredom Scale (MSBS) [17] is the most comprehensive measure of state boredom, while the Boredom Susceptibility Scale (BSS) [29] and the Boredom Proneness Scale (BPS) [21] are the most widely used measures of trait boredom.

The original MSBS [17] measures state boredom with 29 items that sort into 5 factors: disengagement (from the current environment), high arousal (including agitation), inattention (feeling distracted or unfocused), low arousal (feeling down), and time perception (the feeling that time is passing slowly) [46]. A shorter version of the MSBS with 19 items has yielded 4 factors: disengagement, low arousal, inattention, and time perception [52]. A different short-report version of the MSBS includes 10 items tapping disengagement, inattention, and time perception [53]. State boredom scores on the MSBS are associated with trait boredom/boredom proneness $[17,22]$ as well as a range of psychopathology-related constructs including depression, ADHD, impulsivity, anger, and neuroticism [17]. A new measure of state boredom, the SBI [20], includes 11 items that sort into 3 factors (disengagement, low arousal, and inattention), each of which is congruent with 1 of the 5 factors derived from the MSBS. In contrast to the MSBS, the SBI does not include items related to high arousal or time perception. Although the SBI was developed to advance research in organizational settings [20], item content is not specific or restricted to that context.

Common measures of trait boredom or boredom proneness include the BSS [29] and the BPS [21]. As a subscale of the broader Sensation Seeking Scale, the 10item BSS regards boredom as an aversive, restless reaction to experiences that are repetitive, routine, dull, or predictable. The scale contains items that assess a need for change and variety and a strong aversion to redundancy and predictability, most of which reflect boredom produced by a lack of environmental stimulation [16]. The 28-item BPS [21] takes a broader view of trait boredom. The scale yields between 2 and 5 factors [46], the most consistent of which are "internal stimulation" and "external stimulation," which correspond to the degree to which an individual is able to generate interest internally and the degree to which an individual perceives stimulation or variety in the environment [46]. Although both the BPS and the BSS are used to measure trait boredom, they are not highly correlated $[22,54]$, and may be measuring different constructs altogether [46]. Vodanovich and Watt [46] argue that the BSS may measure sensation seeking rather than boredom and recommend that it be used when primary outcomes include risky behaviors related to sensation seeking.

Experimental manipulations or inductions may also shed light on boredom with less reliance on self-report scales. The idea of experimentally inducing boredom is not a new one, and some have successfully done so to examine its antecedents and consequences [e.g., 55, 56]. For example, Fahlman et al. [17] randomized participants to watch one of three 25 -min videos designed to be overstimulating, under-stimulating, or non-boring. Time perception and sense of control were also manipulated to 
maximize feelings of boredom: participants assigned to watch boring videos were made to feel they had no choice over video content and were told that the video would end after $20 \mathrm{~min}$, although it continued for 25 . Hunter et al. [53] used a similar induction. In both of these studies [17, 53], state boredom scores on the MSBS were sensitive to boredom manipulation. Markey et al. [57] provide a useful examination of available inductions, none of which have been tested in clinical populations.

\section{Expanding the View: Boredom Reactivity}

In the context of BPD, it may be useful to move beyond typical valence/arousal and state/trait accounts of boredom to consider boredom sensitivity. In the study of other affective states, including anxiety, sensitivity refers to an individual's fear of or aversive reaction to a specific emotion or its associated sensations [58]. People high on anxiety sensitivity are more prone to a range of anxietyrelated psychopathology [see 59]. Similarly, sensitivity encompasses the notion that individuals may vary not just on how prone they are to experience boredom, but also on the degree to which they fear or avoid that experience. Some may also have more difficulty tolerating boredom when it does occur or may lack coping skills for managing the experience. As with an emotion like anxiety or a sensation like pain, one could feel a great deal of boredom yet tolerate it well, while another individual may feel a lesser degree of boredom and find themselves significantly affected. One may find room for or accept the experience of boredom without efforts to change the experience, or one may react to boredom with cognitive restructuring or behaviors that adaptively reduce the experience (i.e., coping skills). A limited body of work has examined boredom coping [30, 38, 60-63]. Moreover, both the intensity of boredom and the duration of the experience likely vary - it may be mildly negative or short-lasting for some and quite significant and long-lasting for others. Each of these components somewhat characterizes how a person responds to boredom or boredom signals. Danckert et al. [64] have positioned trait boredom as the chronic tendency to react to the boredom signal maladaptively. Considering components of that maladaptive response may advance boredom theory broadly and help clarify boredom's relevance to BPD.

Sensitivity, tolerance, intensity, and duration of emotion are not captured in standard accounts of trait or state boredom. Each of these components of the boredom experience is articulated in Table 1, with predictions for their relevance to BPD. Together, they may be conceptualized as boredom reactivity: some individuals (e.g., those with $\mathrm{BPD}$ ) are likely more sensitive to boredom cues, experience boredom more strongly or with less dependence upon environmental cues, for a longer duration, and in a more consuming, aversive, or overwhelming way. These issues are reflected in our recommendations.

\section{Causes of Boredom}

Comprehensive models regard the momentary, state experience of boredom as the product of a transaction between the individual and the environment [e.g., 34]. Westgate and Wilson [18] propose that state boredom arises when activities or situations are meaningless, and/ or when the attentional demands of a situation are misaligned with a person's current mental resources. The idea that boredom results from meaningless situations likely explains the predominance of workplace research, which typically considers mechanistic tasks that are unlikely to inspire meaning or purpose. Nietzsche $(1878 / 1996)$ warned that industrialization would cause boredom, and the word "boredom" first appeared in the English language at the dawn of the industrial revolution [65].

Westgate and Wilson [18] argue that situations lack meaning when they are incongruent with a person's values, which renders meaninglessness itself a product of both the situation and the person. In other work, perceived meaninglessness is consistently marked as a contributor to boredom $[42,60,66,67]$ or as a component of boredom [68]. Changes in general life meaning predict changes in boredom across time [60], and situational perceptions of meaning are associated with the momentary experience of boredom. For example, in a 7-day experiencing sampling study, perceived meaningless of situations predicted state boredom more so than sadness, personality, and boredom proneness [67]. Moreover, when participants are asked to recall meaningless life events, they report greater levels of state boredom than when asked to recall meaningful events [60]. Functional accounts often position boredom as a marker or signal of low-meaning situations, which drives meaning-seeking behavior $[64,68,69]$. Notably, sense of general life meaning and boredom may have bidirectional influences [60], and momentary boredom may contribute to a sense of situational meaninglessness [68].

State boredom may also arise when a person's attentional resources are misaligned with the cognitive demands of a situation [18]. In other words, a meaningful situation does not ensure a lack of boredom - a person must also be able to focus on the situation to find engagement. Boredom may alert the individual to a lack of 
Table 1. Proposed components of boredom reactivity

\begin{tabular}{|c|c|c|}
\hline Component & Description and measurement & Predictions for BPD \\
\hline Sensitivity & $\begin{array}{l}\text { Fear of or aversive reaction to boredom and/or its associated sensations. } \\
\text { Typically measured via self-report in the study of other affects }\end{array}$ & $\begin{array}{l}\text { Boredom sensitivity is likely high in BPD. } \\
\text { People with BPD will report greater fear or } \\
\text { aversion to boredom, as well as the } \\
\text { propensity to interpret signs (e.g., } \\
\text { sensations, cognitions) of boredom } \\
\text { negatively or catastrophically }\end{array}$ \\
\hline Tolerance & $\begin{array}{l}\text { The degree to which an individual is able to cope with or accept the } \\
\text { experience of boredom. Can be measured subjectively (e.g., self-report) } \\
\text { or objectively (e.g., the amount of time a person is able or willing to } \\
\text { experience boredom without engaging in a behavior or thought process } \\
\text { meant to change or end the experience). Tolerance may depend, in part, } \\
\text { on sensitivity and intensity }\end{array}$ & $\begin{array}{l}\text { Boredom tolerance is likely low in BPD. } \\
\text { People with BPD will make attempts to } \\
\text { escape the feeling of boredom soon after } \\
\text { its onset }\end{array}$ \\
\hline Intensity & $\begin{array}{l}\text { The degree of boredom experienced, and/or the degree of other } \\
\text { emotions experienced as the result of boredom. Typically measured via } \\
\text { self-report in the study of other affects. Psychophysiological assessment } \\
\text { may also be useful }\end{array}$ & $\begin{array}{l}\text { As with other emotions, boredom is likely } \\
\text { experienced intensely for people with BPD }\end{array}$ \\
\hline Duration & $\begin{array}{l}\text { Without external intervention, the length of time that the experience of } \\
\text { boredom (and/or associated emotions) endures. Duration may also } \\
\text { include consideration of how resistant the feeling of boredom is to } \\
\text { change in the face of intervention. Duration and intensity are likely } \\
\text { related. Measured via self-report and time tracking }\end{array}$ & $\begin{array}{l}\text { As with other emotions, the experience of } \\
\text { boredom is likely to endure and to be } \\
\text { difficult to change for people with BPD }\end{array}$ \\
\hline
\end{tabular}

meaning, and/or to a mismatch between the cognitive demands of a task and available mental resources. Understimulating and overstimulating tasks cause boredom because they either underuse or exhaust available mental resources [18]. Eastwood et al. [31] have also argued that attention processes play a prominent role in boredom boredom arises when one is unable to engage attention with external (e.g., activities) or internal (e.g., thoughts) stimuli, is aware of their difficulty engaging attention, and blames the environment. This is consistent with trait boredom's prediction of lesser sustained attention [70], and evidence that boredom arises from difficulties engaging executive control networks during monotonous tasks [71].

People with BPD often struggle to articulate consistent values or sources of meaning in their lives. BPD is also associated with difficulties in attention processes [72-74] and is often comorbid with attention deficit hyperactivity disorder $[75,76]$. To the extent that interventions are able to help people connect with sources of meaning and mitigate attention difficulties, they may be useful for reducing the experience of boredom. We return to this idea in our recommendations.

Boredom in Borderline Personality Disorder

\section{Relation of Boredom to BPD and Its Criteria}

Conceptual definitions and theoretical discussions of boredom often include significant overlap with current diagnostic criteria for BPD or suggest that boredom is relevant to understanding BPD symptoms. Chronic emptiness is the most notable of these symptoms. Other related criteria include identity disturbance, impulsivity, and affective dysregulation.

\section{Boredom and Emptiness}

Research on the differentiation of boredom and emptiness is significantly limited in quantity and fraught with definitional issues. Perhaps most salient of these is a lacking consensus around what emptiness is. Levy [77] argues that the concept of emptiness is frequently used in clinical descriptions as if it has "some generally understood and shared meaning," despite the fact that it has not been defined. A recent comprehensive review [78] confirms that emptiness is poorly defined, theoretically and empirically. Similar to constructs like sadness or joy, emptiness is a subjective description for an emotional state, which manifests idiosyncratically and is therefore difficult to define universally. When asked about the experience of 
emptiness, some people do not understand what is being assessed [6], and people with BPD may have difficulty describing their own experience of emptiness [79]. Further qualitative work may be useful for capturing the full range of subjective experiences. Moreover, a fully articulated state-trait account of emptiness is lacking, as is a clear circumplex mapping of valence and arousal. These lenses have been useful for the study of boredom and may be fruitful for the study of emptiness. A lacking conceptual definition of emptiness is reflected in an extremely limited pool of operational definitions (for a review, see Miller et al. [78]).

Despite these barriers to conceptualization, a comprehensive view of existing literature on emptiness suggests that the experience generally includes a sense of disconnection from self and between self and others [78] which is distinct from, but not entirely unrelated to, feelings of hopelessness, loneliness, intolerance of aloneness, and isolation [78, 80]. Other descriptions of emptiness include the feeling of being "without meaning, purpose, or substance" [6, p. 99], or a "pervasive and visceral sense of detachment spanning intrapersonal, interpersonal, and existential domains of existence" [81, p. 18]. Miller et al. [78] found that, across the literature, chronic emptiness is described as an experience similar to having an internal hole or vacuum, aloneness [82]; feeling swallowed [83]; the feeling of vagueness [84]; a sense of internal absence [85]; woodenness [86]; and numbness or alienation [87].

Although it is common to use the terms boredom and emptiness interchangeably or together [e.g., 88-90], descriptions of the 2 experiences, as well as their causal mechanisms, suggest that the two are distinct. While it is true that both terms connote a sense of disconnection from a sense of meaningful engagement in boredom versus from self or others in emptiness - their non-shared features are significant. In many descriptions, boredom includes a sense of feeling unstimulated, as well as a sense that time is passing slowly. The associated drive is to find a stimulating or engaging activity to aid self-regulation [64]. Descriptions of emptiness do not include these experiences. On the other hand, descriptions of emptiness, but not descriptions of boredom, include a sense of disconnection which is experienced as a painful absence, often felt physically within the body. This is consistent with the idea that emptiness is a more diffuse and existential feeling state than boredom [88]. No known work to date has offered a functional account of emptiness which would suggest its purpose or associated drives. However, evidence suggests that rather than motivating a search for engagement, it is more likely to motivate escape or with- drawal, including suicidal ideation and behavior [ $80,91-$ 93]. Although boredom is associated with self-harming behaviors $[69,94]$, the underlying motivation when bored is more likely to be sensation seeking than disengaging.

Although distinct causal mechanisms can result in similar outcomes, it is notable that causal accounts of boredom and emptiness are largely non-overlapping. As reviewed, boredom can be understood as a signal that alerts an individual to a mismatch between cognitive demands and resources (e.g., attention processes) or a lack of personal meaning. In contrast, emptiness is generally understood as the result of identity disturbance. Accordingly, emptiness falls under the identity disturbance domain in the DSM-5's Alternative Model of Personality Disorders [3]. Theoretically, emptiness is often understood as a product of unstable object relations [83, 9598], a split self $[84,96,99]$, a false self [100], or absent identity [101, 102]. In qualitative and quantitative work, emptiness has been linked to distorted self-image and lack of identity [103], identity diffusion [104], and general deficits in identity [79]. Some have theorized that boredom may also be related to identity disturbance [77], but there has been limited empirical consideration of this association. The association of boredom and identity disturbance is more fully explored in the following section.

There is also empirical evidence to suggest that boredom and emptiness are separate constructs. In one study, Klonsky [80] measured the association of a variety of affect states with feeling "empty inside" in a sample of participants who exhibited self-injuring behavior (regardless of BPD diagnosis). Most notably, boredom and emptiness were not associated in retrospective reports from before and after self-injury and appeared to be separate constructs. This study is limited in its use of retrospective reports and its specific focus on affect states before and after the occurrence of self-injury. Given the lack of statetrait considerations in emptiness research, it is unclear how the momentary experience of emptiness relates to the symptom of chronic emptiness.

Although emptiness and boredom may be separate constructs, there is reason to expect that the two may interact. More specifically, it is possible that the sense of disconnection common in descriptions of emptiness may predispose a person to the experience of boredom. Boredom is often regarded as a state in which a person wants but cannot find meaningful internal stimulation, external stimulation, or both. One is most likely to find this meaningful stimulation when able to connect to self (internal stimulation) or the world (external stimulation). Lack of connection with self or the world is often explained in 
terms of attention processes and meaning in the context of boredom, while this disconnection is usually explained in terms of identity disturbance in the context of emptiness. The extent to which attention and meaning processes are related to identity processes remains unexplored. It is possible that the identity disturbance that underlies chronic feelings of emptiness may contribute to or interact with the mechanisms underlying boredom. Finally, state boredom is thought to result from difficulty finding meaning in the moment. If emptiness includes a chronic difficulty finding meaning or purpose, as has been suggested [6], then it stands to reason that emptiness itself may drive or contribute to boredom. We return to these ideas in our Boredom Cascade Model.

Establishing a better definition of emptiness as experienced by people with BPD and determining whether boredom and emptiness are truly distinct require additional research. There is a significant dearth of empirical research in this area, which ultimately obscures a clear view of the relative importance of emptiness and boredom in the study of BPD. We return to this issue in our recommendations. Nevertheless, there are a number of ways that boredom is relevant to particular features of BPD and to the diagnosis itself.

\section{Boredom and Identity Disturbance}

The third criterion for BPD, "identity disturbance," describes a chronically unstable sense of self reflected in frequent and sudden changes in goals, preferences, and values across realms (e.g., academic/career, social group, sexual orientation [3]). Although little empirical work has examined the association of boredom and identity disturbance in BPD without grouping boredom with emptiness, theoretical work commonly suggests connections. For example, theorists have argued that identity is crucial in regulating cognitive, affective, and behavioral functioning [104-106] and is essential to defining meaningful, realistic goals and engaging in purposeful behavior to achieve them. It follows, then, that identity disturbance may contribute to the perceived meaninglessness that drives boredom, as well as to difficulties using boredom as an adaptive cue to seek out meaningful activities.

Unstructured and minimally stimulating environments are often difficult for people with BPD. This may be because these environments lack meaningful challenge and contribute to the experience of boredom. Without external structure and stimulation, individuals must purposefully seek out or create sources of stimulation. This is a challenging task without a sense of self with stable desires, preferences, and abilities. Theoretically, conflict-

Boredom in Borderline Personality Disorder ing or unstable self-perceptions, combined with problems of self-regulation, interfere with outlining and pursuing meaningful, non-mood-dependent activity [102, 107] and may thereby increase susceptibility to boredom in the context of minimal external structure or stimulation. Difficulties with attentional control, which affect both self-regulatory functioning and the ability to voluntarily (rather than impulsively) direct attention and control behavior [108], have been empirically demonstrated in $\operatorname{BPD}[73,109,110]$ and likely further contribute to boredom in unstructured environments.

Additionally, for individuals lacking a stable sense of self, situations that require decision-making are theorized to be highly dysregulating and to induce an "avoidance of choices" that fuels boredom, detachment, alienation, and paralysis [107]. Because uncertainty about outcomes and unrealistically high expectations for one's performance can elicit feelings of failure and/or anxiety, fear, guilt, shame, and frustration [102], tasks involving planning, goal setting, or decision-making are often abandoned quickly or avoided altogether by people with BPD. People with BPD have demonstrated unwillingness to experience distress in order to pursue goal-directed behavior [111], which may impede the ability to use boredom as an adaptive signal. The inability to make decisions or commit to activities can be a form of avoidance that both reflects and exacerbates feelings of purposelessness, disconnection, boredom, and "generalized malaise" [112]. This pattern reinforces a lack of agency, prolongs the absence of meaningful, goal-directed activity, and further entrenches passive, indifferent attitudes toward life. Over time, boredom can evolve into hopelessness through this association with a lack of goals, direction, motivation, and sense of meaning or purpose [21].

\section{Boredom, Impulsivity, and Affect Regulation}

In contrast to the theoretically dominated literature on identity disturbance, there is a growing pool of empirical evidence linking impulsivity and affect regulation with boredom. Consistent with the low-arousal nature of boredom, it can produce lethargic, anhedonic responses in BPD [113]. However, it is also associated with impulsive behavior in non-clinical populations [114]. Impulsivity has long been recognized as a core feature of BPD [115, $116]$, and manifests in a variety of ways, including spending, risky sex, substance abuse, shoplifting, reckless driving, and binge eating [3]. Self-harm (i.e., cutting, burning, skin picking), often enacted impulsively, is another discriminating marker and criterion for BPD. These behaviors are generally understood as maladaptive attempts to 
avoid, regulate, or escape from overwhelming and intolerable negative affect [117-122], and people with BPD report significant short-term relief or release from intense negative emotions immediately following self-harm $[121,123]$.

In non-clinical populations, impulsivity may be understood, in part, as a reaction to boredom [114]. This may also be true in clinical populations. For example, Maggini [124] described boredom as an "affective state that drives excessive, abnormal, and impulsive behaviors... aimed to mitigate or avoid it" (p. 25). If a person with BPD lacks a sense of how to mitigate boredom adaptively through engagement with valued activities, they may resort to highly arousing maladaptive behaviors to escape the experience. Additionally, the desire to generate feelings [117], regain awareness of physical sensations or reality [72], or end feelings of dissociation [125-127], which may be related to boredom $[77,106]$, may contribute to non-suicidal self-injury in BPD. Unsurprisingly, then, the aversive experience of boredom has been directly identified as an antecedent of deliberate self-harm among women with BPD [94] and self-inflicted painful shock among undergraduates, particularly those with a history of self-harm [128].

It is also possible that boredom may function as a moderator between dysregulated affect and impulsivity by impeding efforts to use external stimuli to contain or avoid intense emotions. People with BPD rely heavily upon external structures for emotion regulation, as they provide distraction or means to avoid negative emotional states. For example, watching a funny video may provide distraction from negative thoughts or feelings. However, the inability to self-generate meaningful engagement with an environment perceived as boring may preclude this avoidance and thereby amplify awareness of internal experiences - a funny video will not provide distraction when a person is unable to sufficiently engage with it or finds it boring. Failure to find distraction may then create additional negative thought or emotion or heighten awareness of pre-existing negative thoughts or emotion. This may then trigger problematic impulsivity or escalating behavioral attempts to find distraction in the external environment.

\section{Boredom, BPD, and Other Diagnoses}

Given boredom's association with major features of $\mathrm{BPD}$, including emptiness, identity disturbance, impulsivity, and affective dysregulation, it is not surprising that boredom has been linked to the BPD diagnosis in adolescents [113] and adults [88]. Although the transdiagnostic manifestation of boredom across disorders is beyond the scope of the current review, it is important to note that boredom is not specific to BPD and often endorsed in other psychopathology, including mood and anxiety disorders [13, 129-131]. Some have found that boredom effectively discriminates people with BPD from healthy, but not psychiatric, controls [132], while other findings suggest no differences in boredom between participants with BPD and healthy controls or participants with major depressive disorder [133]. As is generally the case in the study of boredom in BPD, this work is extremely limited.

The experience of boredom in other personality disorders is common [88] and of particular relevance, given that the removal of boredom from the BPD criteria was partially motivated by its importance to narcissistic and antisocial personality disorders $[4,6]$. However, the empirical literature on narcissism, psychopathy, and boredom is minimal, and has been conducted primarily in non-clinical samples. Indeed, there is little evidence about boredom's role in antisocial personality disorder per se. Still, boredom proneness is included in the primary measure of psychopathy: the Psychopathy Checklist-Revised (PCL-R) [134]. The role that boredom plays in psychopathy is likely connected to the need for stimulation. Similar to how people with BPD react to boredom, the negative activation that results from boredom may lead people with psychopathy to engage in destructive, risky, and aggressive behaviors as forms of experiential avoidance $[135,136]$.

Theoretical formulations often include the importance of boredom in narcissism [e.g., 137, 138], yet empirical findings are somewhat mixed. Wink and Donahue [139] found that overt narcissism, characterized by high levels of extroversion and rebellious behavior, correlated with aspects of boredom including restlessness and impatience as a result of a lack of external stimulation, while covert narcissism, which is identified by an anxious, depressed, introverted, vulnerable inner self, correlated with aspects of boredom related to difficulties in internal stimulation, meaninglessness, and the perception of slow time passage. Both types of narcissism correlated positively with a need for external stimulation. In contrast, Zondag [140] found a positive correlation between overt narcissism and boredom but a negative correlation between covert narcissism and boredom.

A lack of standardized assessment of boredom in clinical populations has limited the comparative evaluation of boredom in BPD versus other disorders. Nevertheless, existing literature suggests a strong, while not specific, link between BPD and boredom. Clinical and theoretical 


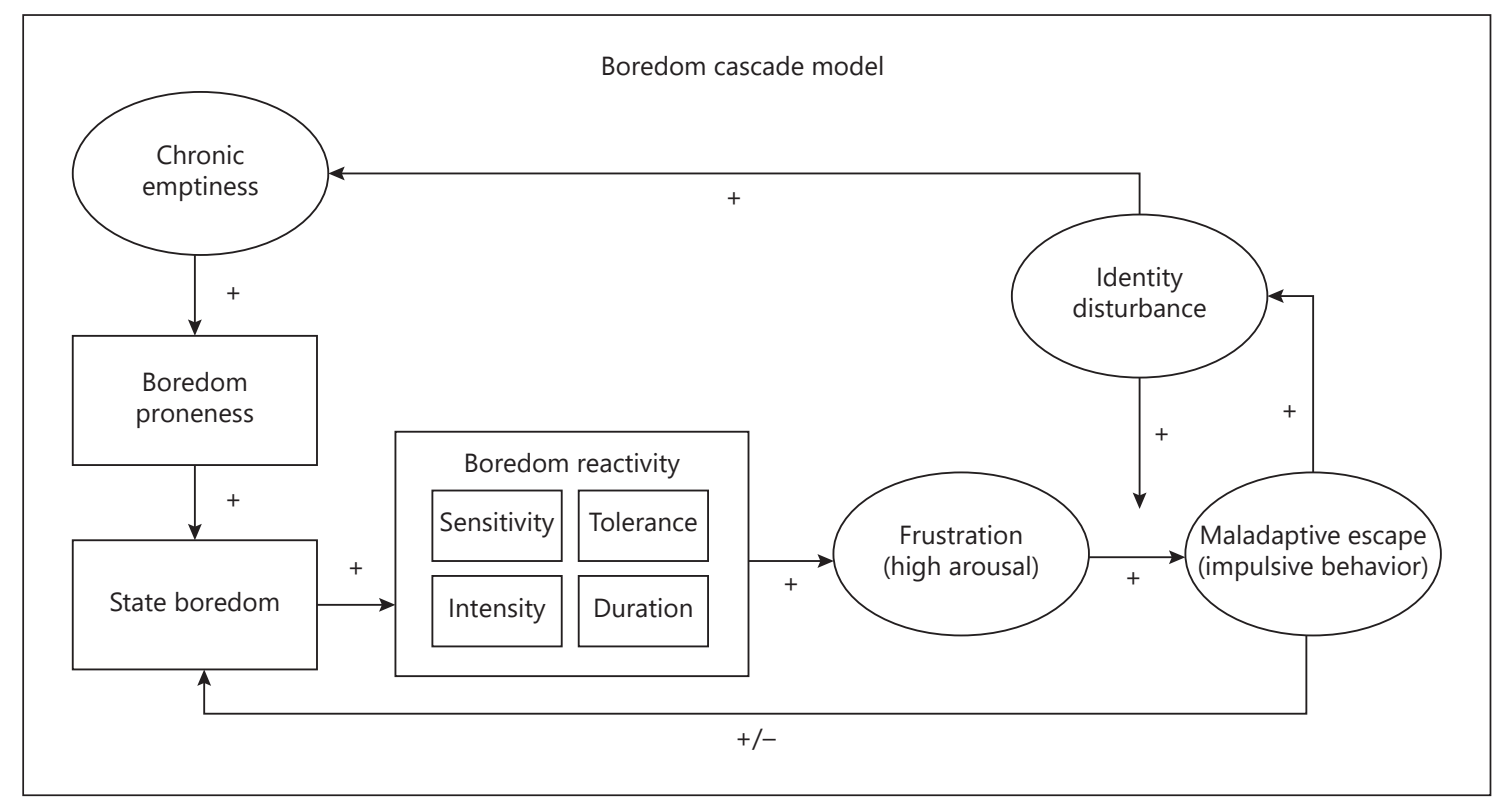

Fig. 1. Boredom cascade model. State boredom results in high arousal frustration, particularly when individuals are high on boredom reactivity, comprised of sensitivity, tolerance, intensity, and duration. An adaptive response to boredom would include seeking meaningful engagement. However, identity disturbance may obscure a sense of meaning or values, leaving the person with $\mathrm{BPD}$ to engage in maladaptive escape behaviors. This response may exacerbate identity disturbance or preclude identity develop-

perspectives suggest that deficits in the capacity for selfregulation, which are central to $\mathrm{BPD}$, are highly relevant to boredom proneness and intolerance in the disorder. Particular features of BPD, including identity disturbance and impulsivity, are potentially related and/or consequence of high vulnerability and reactivity to boredom.

\section{A Boredom Cascade Model}

Converging evidence concerning boredom's role in BPD supports a Boredom Cascade Model. Cascade models posit positive feedback loops in which an emotional experience contributes to a specific outcome, often behavioral, which itself makes the initial emotional experience more likely an/or more intense [141]. Emotional cascade models have been proposed to understand the influence of negative affect and rumination on self-injury [142] and the broad association of emotional and behavioral dysregulation in BPD [143]. The Boredom Cascade model focuses on the manner in which boredom and boredom reactivity contribute to behavioral dysregula- ment, which fuels chronic emptiness, boredom proneness, and later instances of boredom. Maladaptive escape may sometimes alleviate state boredom, in which case the cascade will terminate. However, when these escape attempts fail, they may exacerbate state boredom and boredom reactivity, which may in turn lead to escalating escape patterns characterized by increasingly impulsive or sensation-seeking behavior. This model is not exhaustive (e.g., not all causal factors are depicted).

tion. More specifically, the model posits that boredom reactivity (outlined in Table 1) mediates an association between state boredom and high-arousal frustration or distress. In the absence of stable identity or a sense of values or sources of meaning, a person with BPD has difficulty coping with this frustration adaptively, through the pursuit of meaningful goal-directed activity. Instead, they may engage in impulsive or sensation-generating behaviors. This maladaptive response may exacerbate identity disturbance or preclude opportunities to build stable identity through engagement with meaningful activities. Identity disturbance may then fuel chronic emptiness, which in this model we have positioned as one potential contributor to boredom proneness and state boredom (through boredom proneness). Engaging in maladaptive behaviors may sometimes reduce state boredom. However, these behaviors are still maladaptive because of their inherent risk and consequences for identity development. When maladaptive behaviors fail to mitigate state boredom, this may lead to further boredom or boredom reactivity, greater frustration, and escalating patterns of maladaptive response, characterized by increasingly impul- 
sive or sensation-seeking behavior. A basic outline of this model is depicted in Figure 1. Notably, this model does not include all potential causes of boredom or emptiness, or all causes included in this review (e.g., attention processes). Rather, it provides a simplified account of how boredom and boredom reactivity may interact with identity disturbance and emptiness to create an escalating pattern of dysregulated behavior.

In positioning chronic emptiness as one potential contributor to boredom proneness (and thereby state boredom), we do not mean to suggest that boredom is itself a component of chronic emptiness or simply a more easily observed manifestation of chronic emptiness. Instead, this suggests that chronic emptiness and boredom interact in significant ways for people with BPD. Chronic emptiness may predispose a person to have difficulty finding meaning or connection with their internal and external worlds, fueling a sense of boredom across contexts. So too does boredom influence emptiness: the high arousal frustration that results when a person is highly reactive to boredom precludes opportunities to pursue activities that may alleviate identity disturbance and chronic emptiness. Although emptiness may better discriminate people with BPD than boredom, the consideration of boredom is likely to provide insights into chronic emptiness, one of the least understood aspects of BPD. The Cascade Model of Boredom also suggests that boredom is highly clinically relevant, and that interventions aimed at directing people toward finding meaning or maintaining goal pursuit when they feel bored will have cascading benefits.

\section{Summary and Recommendations}

Although boredom was removed from the BPD criteria on the basis of seemingly limited, unpublished information, it is unclear whether the change was appropriate. The state of the current research is simply not conclusive. Regardless of whether or not boredom belongs in the diagnostic criteria for BPD, it is clear that boredom is relevant to $B P D$, and that further research is necessary. Based on our review of the literature, there are a few areas most in need of inquiry.

Taking a broad view of the literature, it is apparent that emptiness and boredom are quite frequently measured or conceptualized as the same construct, despite initial evidence that they may be independent of one another. This obscures a clear sense of diagnostic changes made to the emptiness criterion, and will continue to obscure our understanding of both experiences.
1. Empirical studies should take advantage of existing boredom measures to assess boredom independent of emptiness. Given their long history of enmeshment, further work is also necessary to fully disentangle these two constructs. It may be helpful to start with qualitative approaches to better understand how people experience both boredom and emptiness. For a review of boredom measures, see Vodanovich and Watt [46]. For a review of emptiness measures, see Miller et al. [78].

As Vodanovich and Watt [46] outline, there are many boredom measures, and more have been developed since their review. However, these measures are limited in a number of ways, including but not limited to their focus on organizational behavior, contextual specificity, and lack of validation for clinical populations.

2. Existing boredom scales should be validated for use in clinical populations, and/or new scales with clinically relevant predictive validity should be developed. In the absence of scales with clear clinical utility, we recommend the BPS as a measure of boredom proneness, given its well-replicated psychometric support. Both the MSBS and the SBI are appropriate measures of state boredom.

3. It is clear that existing boredom measures may tap different underlying constructs. For this reason, scales should be chosen carefully for clinical research, based on both their psychometric properties and their item content. For example, choosing the BSS, which focuses largely on sensation-seeking, may inflate boredom's importance in psychopathology characterized by sensation-seeking. In the context of BPD, the BSS may be useful when the primary outcome of interest is behavioral dysregulation, but is likely to underestimate the importance of boredom for other sectors of BPD psychopathology.

Because there are so many self-report measures of boredom, we hesitate to recommend another, yet a review of scale content and existing literature suggests that we may be missing important aspects of how boredom is experienced.

4. Following on work related to anxiety, pain, and other aversive states, the study of boredom will benefit from consideration of boredom sensitivity (i.e., how much an individual is aware of and negatively impacted by sensations of boredom), tolerance (i.e., how much boredom an individual is willing to experience), intensity, and duration. Together, these components comprise boredom reactivity.

5. Experimental manipulation or induction of boredom may be particularly useful for examining boredom re- 
activity, behavioral consequences (i.e., what urges arise to mitigate the experience, how these translate to action, decision-making), and other consequences (e.g., effects on cognition or emotion).

This review focuses largely on the personality disorder model that has predominated the treatment and research landscape since DSM-III. However, the tide of research in personality disorders is increasingly turning toward dimensional models. Boredom's role in BPD - and psychopathology more broadly - should be included in this progression. 6. We have reviewed boredom's relevance to facets of BPD, as well as general individual differences that may make an individual more boredom prone. Each of these, and boredom itself, can be conceptualized using the DSM alternative model (for a review see [144]). In this model, personality functioning is evaluated in terms of self (identity and self-direction) and interpersonal functioning (empathy and intimacy). Pathological personality traits are organized into 5 domains (negative affectivity, detachment, antagonism, disinhibition, and psychoticism). It may be useful to evaluate boredom's relation to these domains, which align well with general personality models.

7. Boredom may also be conceptualized using general models of personality. For example, in the context of the Five Factor Model [see 145], boredom is positively associated with neuroticism [146-148] and negatively associated with agreeableness and conscientiousness $[146,148,149]$. Boredom's relation to extraversion is less clear (e.g., see $[150,151])$. In the HEXACO model of personality [137], aspects of boredom are related to honesty/humility, emotionality, conscientiousness, extraversion, and openness [152]. Others have used HEXACO to explore the associations among personality, boredom, and creativity [153]. Other models of psychopathology and personality, including HiTOP [154], may be useful for understanding boredom transdiagnostically.

8. Some have argued that BPD is best understood as the manifestation of a general predisposition to psychopathology [e.g., 155]. Future research should consider how broad factors like general negative affect or neuroticism may explain boredom's associations with BPD features and other psychopathology.

9. We have proposed a Boredom Cascade Model, in which the experience of boredom and boredom reactivity interact with identity disturbance and chronic emptiness to cause escalating behavioral dysregulation. Cascading relationships of this type have recently become the focus of a trend to examine network models of psychopathology, in which disorders consist in the causal interplay of symptoms [156]. The inclusion of boredom in this type of model would allow for a relatively direct test of its relevance to BPD, as well as evaluation of how boredom and emptiness interact. Finally, this review suggests some specific directions for clinical practice and treatment research.

10. Boredom may result from a sense of meaninglessness. This may be exacerbated for people with BPD, who have difficulty with self-direction and identity instability. Fortunately, there are a number of ways that treatments for BPD integrate building a life of purpose and meaning. For example, Dialectical Behavior Therapy (DBT) [102] was designed in part to help patients build a "life worth living." For boredom-prone individuals, DBT may be bolstered with the integration of Acceptance and Commitment Therapy (ACT) [157], which has an explicit focus on limiting experiential avoidance to promote value-driven behaviors. The integration of ACT into DBT has been suggested by others as a means to promote treatment motivation [158], and it is worth testing whether this integration is also useful for boredom and its consequences. Generalist models for BPD are also poised to address issues with boredom: Good Psychiatric Management (GPM) [159], for example, emphasizes building a productive life through work.

11. For some, the focus on goals, values, and building a life may not be enough to alleviate boredom or address its consequences. The mindfulness and distress tolerance modules of DBT may be particularly useful for managing boredom, through the cultivation of connection to internal states and the present moment, as well as the development of specific skills for tolerating unpleasant emotion. The mindfulness component of DBT has also been shown to improve attention [160], which may support activity engagement. Although there is little empirical work on boredom's association with mindfulness, what does exist confirms the notion that boredom proneness is negatively associated with mindfulness [161]. Ongoing research on mindfulness and boredom is preregistered on OSF [162], and this work should be extended to clinical contexts.

\section{Conclusions}

Although boredom is no longer part of the diagnostic criteria for BPD, it remains both prevalent and problematic in the disorder. While the existing literature does not 
suggest boredom is specifically discriminating for BPD, this literature is limited, and problems of boredom proneness and intolerance are clinically relevant. Inconsistencies in the definition and measurement of boredom present obstacles to evaluating its importance to BPD. However, growing theoretical and empirical research suggests associations between boredom proneness and many aspects of the BPD diagnosis. Clinical experience corroborates the relevance of boredom to numerous BPD features. We propose the relationships between boredom and impulsivity, affect regulation, and identity disturbance in BPD are highly important and merit attention in both research and treatment. Consideration of proposed elements of boredom reactivity and the Boredom Cascade Model may provide useful insights into the nature of BPD and potential interventions.

Although we remain agnostic about whether the decision to remove boredom from the diagnostic criteria for BPD was appropriate, it is clear that the revision was made on the basis of limited data. The decision to exclude boredom due to its prevalence in other patient populations signifies an effort to increase the specificity and discriminative power of the diagnostic criteria for BPD. While these revisions increase the ability to discriminate one disorder from another, they may lead clinicians to overlook or underestimate the importance of symptoms like boredom simply because they are prevalent in mul- tiple disorders. Going forward, it is important to consider the significance of boredom - as potentially separate from emptiness - to BPD in both research and practice.

\section{Acknowledgement}

We thank Molly Lewen, MD, for her work on the earliest versions of the manuscript.

\section{Conflict of Interest Statement}

The authors have no conflicts of interest to declare.

\section{Funding Sources}

This research was not funded by any external funding agency.

\section{Author Contributions}

S.R.M. took primary responsibility for conceptual development, organization, and writing. T.V.S. contributed to conceptual development, drafted and edited portions of the manuscript, and handled formatting tasks. L.W.C.-K. made substantial contributions to conceptual development and manuscript editing.

\section{References}

1 Diagnostic and statistical manual of mental disorders. DSM-3. American Psychiatric Association; 1980

2 Diagnostic and statistical manual of mental disorders. DSM-IV. Washington, DC: American Psychiatric Association; 1994.

3 American Psychiatric Association. Diagnostic and statistical manual of mental disorders (DSM-5). American Psychiatric Pub; 2013.

4 Gunderson JG, Zanarini MC, Kisiel CL. Borderline personality disorder: A review of data on DSM-III-R descriptions. J Personal Disord. Win. 1991;5(4):340-52.

5 Ronningstam E, Gunderson J. Differentiating borderline personality disorder from narcissistic personality disorder. J Pers Disord. 1991;5(3):225-32.

6 Widiger TA, Mangine S, Corbitt EM, Ellis CG, Thomas GV. Personality Disorder Interview-IV: A structured interview for the assessment of personality disorders. Odessa, FL: Psychological Assessment Resources; 1995.

7 Kernberg OF. Severe personality disorders: Psychotherapeutic strategies. New Haven, CT: Yale University Press; 1986.
8 Grilo CM, McGlashan TH, Morey LC, Gunderson JG, Skodol AE, Shea MT, et al. Internal consistency, intercriterion overlap and diagnostic efficiency of criteria sets for DSMIV schizotypal, borderline, avoidant and obsessive-compulsive personality disorders. Acta Psychiatr Scand. 2001 Oct;104(4):26472.

9 Johansen M, Karterud S, Pedersen G, Gude T, Falkum E. An investigation of the prototype validity of the borderline DSM-IV construct. Acta Psychiatr Scand. 2004 Apr;109(4):289-98.

10 Leong FT, Schneller GR. Boredom proneness: temperamental and cognitive components. Pers. Individ. 1993 Jan;14(1):233-9.

11 Watt JD, Vodanovich SJ. Relationship between boredom proneness and impulsivity. Psychol Rep. 1992 Jun;70(3, Pt 1):688-90.

12 Rupp DE, Vodanovich SJ. The role of boredom proneness in self-reported anger and aggression. J Soc Behav Pers. 1997 Dec;12(4): 925-36.

13 Sommers J, Vodanovich SJ. Boredom proneness: its relationship to psychological- and physical-health symptoms. J Clin Psychol. 2000 Jan;56(1):149-55.
14 McGiboney GW, Carter C. Boredom proneness and adolescents' personalities. Psychol Rep. 1988 Dec;63(3):741-2.

15 Watt JD, Vodanovich SJ. Boredom proneness and psychosocial development. J Psychol: Interdisciplinary and Applied. 1999 May; 133(3):303-14.

16 Vodanovich SJ. Psychometric measures of boredom: A review of the literature. J Psychol: Interdisciplinary and Applied. 2003 Nov; 137(6):569-95.

17 Fahlman SA, Mercer-Lynn KB, Flora DB, Eastwood JD. Development and validation of the Multidimensional State Boredom Scale. Assessment. 2013 Feb;20(1):68-85.

18 Westgate EC, Wilson TD. Boring thoughts and bored minds: the MAC model of boredom and cognitive engagement. Psychol Rev. 2018 Oct;125(5):689-713.

19 Posner J, Russell JA, Peterson BS. The circumplex model of affect: an integrative approach to affective neuroscience, cognitive development, and psychopathology. Dev Psychopathol. 2005;17(3):715-34. 
20 Baratta PL, Spence JR. Capturing the noonday demon: Development and validation of the State Boredom Inventory. Eur J Work Organ Psychol. 2018;27(4):477-92.

21 Farmer R, Sundberg ND. Boredom proneness: The development and correlates of a new scale. J Pers Assess. Spring. 1986;50(1): 4-17.

22 Mercer-Lynn KB, Bar RJ, Eastwood JD. Causes of boredom: the person, the situation, or both? Pers Individ. 2014 Jan;56:122-6.

23 Struk AA, Scholer AA, Danckert J. A self-regulatory approach to understanding boredom proneness. Cogn Emotion. 2016 Nov;30(8): 1388-401.

24 Watt JD, Blanchard MJ. Boredom proneness and the need for cognition. J Res Pers. 1994 Mar;28(1):44-51.

25 Seib HM, Vodanovich SJ. Cognitive correlates of boredom proneness: the role of private self-consciousness and absorption. J Psychol. 1998 Nov;132(6):642-52.

26 Hill AB. Work variety and individual differences in occupational boredom. J Appl Psychol. 1975 Feb;60(1):128-31.

27 Hill AB, Perkins RE. Towards a model of boredom. Br J Psychol. 1985 May;76(2):23540.

28 Harris MB. Correlates and characteristics of boredom proneness and boredom. J Appl Soc Psychol. 2000 Mar;30(3):576-98.

29 Zuckerman M. Sensation seeking: Beyond the optimal level of arousal. Hillsdale (NJ): L. Erlbaum Associates; 1979.

30 Eastwood JD, Cavaliere C, Fahlman SA, Eastwood AE. A desire for desires: boredom and its relation to alexithymia. Pers Individ. 2007 Apr;42(6):1035-45.

31 Eastwood JD, Frischen A, Fenske MJ, Smilek $D$. The unengaged mind: defining boredom in terms of attention. Perspect Psychol Sci. 2012 Sep;7(5):482-95.

32 Gerritsen CJ, Toplak ME, Sciaraffa J, Eastwood J. I can't get no satisfaction: potential causes of boredom. Conscious Cogn. 2014;27: 27-41.

33 Malkovsky E, Merrifield C, Goldberg Y, Danckert J. Exploring the relationship between boredom and sustained attention. Exp Brain Res. 2012 Aug;221(1):59-67.

34 Mikulas WL, Vodanovich SJ. The essence of boredom. Psychol Rec. 1993;43(1):3-12.

35 Reijseger G, Schaufeli WB, Peeters MC, Taris TW, van Beek I, Ouweneel E. Watching the paint dry at work: Psychometric examination of the Dutch Boredom Scale. Anxiety Stress Coping. 2013 Sep;26(5):508-25.

36 Schaufeli WB, Salanova M. Burnout, boredom and engagement in the workplace. In: Peeters MC, De Jonge J, Taris TW, editors. An introduction to contemporary work psychology. Wiley-Blackwell; 2014. pp. 293-320.

37 Vogel-Walcutt JJ, Fiorella L, Carper T, Schatz $\mathrm{S}$. The definition, assessment, and mitigation of state boredom within educational settings: A comprehensive review. Educ Psychol. 2012 Mar;24(1):89-111.
38 Goldberg YK, Eastwood JD, Laguardia J, Danckert J. Boredom: an emotional experience distinct from apathy, anhedonia, or depression. J Clin Psychol. 2011 Jun;30(6):64766.

39 Russell JA. A circumplex model of affect. Pers Soc Psychol. 1980 Dec;39(6):1161-78.

40 Yik M, Russell JA, Steiger JH. A 12-point circumplex structure of core affect. Emotion. 2011 Aug;11(4):705-31.

41 Berlyne DE. Conflict, arousal, and curiosity. New York (NY): McGraw-Hill Book Company; 1960. https://doi.org/10.1037/11164-000.

42 Fiske DW, Maddi SR. Functions of varied experience. Oxford: Dorsey; 1961.

43 Hebb DO. Drives and the C N S (conceptual nervous system). Psychol Rev. 1955 Jul;62(4): 243-54.

44 O'Hanlon JF. Boredom: practical consequences and a theory. Acta Psychol (Amst). 1981 Oct;49(1):53-82.

45 Merrifield C, Danckert J. Characterizing the psychophysiological signature of boredom. Exp Brain Res. 2014 Feb;232(2):481-91.

46 Vodanovich SJ, Watt JD. Self-Report Measures of Boredom: An Updated Review of the Literature. J Psychol. 2016 Feb;150(2):196-228.

47 Grubb EA. Assembly Line Boredom and Individual Differences in Recreation Participation. J Leis Res. 1975 Sep;7(4):256-69.

48 Lee TW. Toward the development and validation of a measure of job boredom. Manhattan College Journal of Business. 1986;15:22-8.

49 Iso-Ahola SE, Weissinger E. Perceptions of boredom in leisure: Conceptualization, reliability and validity of the Leisure Boredom Scale. J Leis Res. 1990;22(1):1-17.

50 Ragheb MG, Merydith SP. Development and validation of a multidimensional scale measuring free time boredom. Leis Stud. 2001 Jan; 20(1):41-59.

51 Harasymchuk C, Fehr B. Development of a prototype-based measure of relational boredom. Pers Relatsh. 2012;19(1):162-81.

$52 \mathrm{Ng} \mathrm{AH}$, Liu Y, Chen JZ, Eastwood JD. Culture and state boredom: A comparison between European Canadians and Chinese. Pers Individ Dif. 2015 Mar;75:13-8

53 Hunter JA, Dyer KJ, Cribbie RA, Eastwood JD. Exploring the utility of the Multidimensional State Boredom Scale. Eur J Psychol Assess. 2016;32(3):241-50.

54 Mercer KB, Eastwood JD. Is boredom associated with problem gambling behaviour? It depends on what you mean by 'boredom'. Int Gambl Stud. 2010 Apr;10(1):91-104.

55 Bench SW, Lench HC. On the Function of Boredom. Behav Sci (Basel). 2013 Aug;3(3): 459-72.

56 Bench SW, Lench HC. Boredom as a seeking state: boredom prompts the pursuit of novel (even negative) experiences. Emotion. 2019; 19(2):242-54.

57 Markey A, Chin A, Vanepps EM, Loewenstein G. Identifying a reliable boredom induction. Percept Mot Skills. 2014 Aug;119(1): $237-53$.
58 Reiss S, Peterson RA, Gursky DM, McNally RJ. Anxiety sensitivity, anxiety frequency and the prediction of fearfulness. Behav Res Ther. 1986 Jan;24(1):1-8.

59 Olatunji BO, Wolitzky-Taylor KB. Anxiety sensitivity and the anxiety disorders: A metaanalytic review and synthesis. Psychol Bull. 2009 Nov; 135(6):974-99.

60 Fahlman SA, Mercer KB, Gaskovski P, Eastwood AE, Eastwood JD. Does a lack of life meaning cause boredom? Results from psychometric, longitudinal, and experimental analyses. J Soc Clin Psychol. 2009 Mar;28(3): $307-40$.

61 Game AM. Workplace boredom coping: Health, safety, and HR implications. Person Rev. 2007 Aug;36(5):701-21.

62 Hamilton JA, Haier RJ, Buchsbaum MS. Intrinsic enjoyment and boredom coping scales: validation with personality, evoked potential and attention measures. Pers Individ Dif. 1984 Jan;5(2):183-93.

63 Workman JE, Studak CM. Relationships among fashion consumer groups, locus of control, boredom proneness, boredom coping and intrinsic enjoyment. Int J Consum Stud. 2007 Jan;31(1):66-75.

64 Danckert J, Mugon J, Struk A, Eastwood J. Boredom: What Is It Good For? In: Lench HC, editor. The Function of Emotions: When and Why Emotions Help Us. Cham: Springer International Publishing; 2018. pp. 93-119.

65 Spacks PM. Boredom: the literary history of a state of mind. Chicago: The Univ. of Chicago Press; 1996

66 Landon PB, Suedfeld P. Information and meaningfulness needs in sensory deprivation. Psychon Sci. 1969;17(4):248.

67 Chan CS, van Tilburg WA, Igou ER, Poon CY, Tam KY, Wong VU, et al. Situational meaninglessness and state boredom: cross-sectional and experience-sampling findings. Motiv Emot. 2018 Aug;42(4):555-65.

68 van Tilburg WA, Igou ER. On boredom: lack of challenge and meaning as distinct boredom experiences. Motiv Emot. 2012 Jun;36(2): 181-94.

69 Barbalet JM. Boredom and social meaning. $\mathrm{Br}$ J Sociol. 1999 Dec;50(4):631-46.

70 Hunter A, Eastwood JD. Does state boredom cause failures of attention? Examining the relations between trait boredom, state boredom, and sustained attention. Exp Brain Res. 2018 Sep;236(9):2483-92.

71 Danckert J, Merrifield C. Boredom, sustained attention and the default mode network. Exp Brain Res. 2018 Sep;236(9):2507-18.

72 Kleindienst N, Bohus M, Ludäscher P, Limberger M, Kuenkele K, Ebner-Priemer U, et al. Motives for Nonsuicidal Self-Injury Among Women With Borderline Personality Disorder. J Nerv Ment Dis. 2008 Mar;196(3):230-6.

73 Posner MI, Rothbart MK, Vizueta N, Levy KN, Evans DE, Thomas KM, et al. Attentional mechanisms of borderline personality disorder. Proc Natl Acad Sci USA. 2002 Dec; 99(25):16366-70 
74 Seres I, Unoka Z, Bódi N, Aspán N, Kéri S. The neuropsychology of borderline personality disorder: relationship with clinical dimensions and comparison with other personality disorders. J Pers Disord. 2009 Dec;23(6):55562.

75 Ferrer M, Andión Ó, Matalí J, Valero S, Navarro JA, Ramos-Quiroga JA, et al. Comorbid attention-deficit/hyperactivity disorder in borderline patients defines an impulsive subtype of borderline personality disorder. J Pers Disord. 2010 Dec;24(6):812-22.

76 Philipsen A, Limberger MF, Lieb K, Feige B, Kleindienst N, Ebner-Priemer U, et al. Attention-deficit hyperactivity disorder as a potentially aggravating factor in borderline personality disorder. Br J Psychiatry. 2008 Feb; 192(2):118-23.

77 Levy ST. Psychoanalytic Perspectives On Emptiness. J Am Psychoanal Assoc. 1984; 32(2):387-404.

78 Miller CE, Townsend ML, Day NJ, Grenyer BF. Measuring the shadows: A systematic review of chronic emptiness in borderline personality disorder. PLoS One. 2020 Jul; 15(7):e0233970.

79 Rebok F, Teti GL, Fantini AP, Cárdenas-Delgado C, Rojas SM, Derito MN, et al. Types of borderline personality disorder (BPD) in patients admitted for suicide-related behavior. Psychiatr Q. 2015 Mar;86(1):49-60.

80 Klonsky ED. What is Emptiness? Clarifying the 7th Criterion for Borderline Personality Disorder. J Pers Disord. 2008 Aug;22(4):41826.

81 Price A, Mahler H, Hopwood C. Subjective Emptiness: A Clinically Significant Trans-diagnostic Psychopathology Construct. 2019; (pre-print).

82 Lamprell M. From emptiness to loss: A journey from the intrapersonal to the interpersonal. Br J Psychother. 1994;10(3):331-43.

83 Kernberg OF. Borderline personality organisation. J Am Psychoanal Assoc. 1967;15(3): 641-85.

84 Singer M. The Experience of Emptiness in Narcissistic and Borderline States: II. the Struggle for a Sense of Self and the Potential for Suicide. Int Rev Psychoanal. 1977;4:4719.

85 Kernberg OF. Severe Personality Disorders: Psychotherapeutic Strategies. United States of America: Yale University; 1984.

86 LaFarge L. Emptiness as defense in severe regressive states. J Am Psychoanal Assoc. 1989; 37(4):965-95.

87 Fuchs T. Fragmented selves: temporality and identity in borderline personality disorder. Psychopathology. 2007;40(6):379-87.

88 Zanarini MC, Gunderson JG, Frankenburg FR, Chauncey DL. Discriminating borderline personality disorder from other axis II disorders. Am J Psychiatry. 1990 Feb;147(2):1617.
89 Mavissakalian MR, Hamann MS, Haidar SA, de Groot CM. Correlates of DSM-III personality disorder in generalized anxiety disorder. J Anxiety Disord. 1995;9(2):103-15.

90 Becker DF, McGlashan TH, Grilo CM. Exploratory factor analysis of borderline personality disorder criteria in hospitalized adolescents. Compr Psychiatry. 2006 Mar; 47(2):99-105.

91 Harford TC, Chen CM, Kerridge BT, Grant $\mathrm{BF}$. Borderline personality disorder and violence toward self and others: A national study. J Pers Disord. 2018;32:1-18.

92 Trull TJ, Widiger TA. The relationship between borderline personality disorder criteria and dysthymia symptoms. J Psychopathol Behav Assess. 1991;13(2):91-105.

93 Schnyder U, Valach L, Bichsel K, Michel K. Attempted suicide: do we understand the patients' reasons? Gen Hosp Psychiatry. 1999 Jan;21(1):62-9.

94 Chapman AL, Dixon-Gordon KL. Emotional antecedents and consequences of deliberate self-harm and suicide attempts. Suicide Life Threat Behav. 2007 Oct;37(5):543-52.

95 Kernberg O. The treatment of patients with borderline personality organization. Int J Psychoanal. 1968;49:600-19.

96 Kernberg O. Borderline conditions and pathological narcissism. New York: Aronson; 1975.

97 Masterson JF, Rinsley DB. The borderline syndrome: the role of the mother in the genesis and psychic structure of the borderline personality. Int J Psychoanal. 1975;56:16377.

98 Masterson JF. Psychotherapy of the borderline adult: A developmental approach. New York: Brunner Mazel; 1976.

99 Westen D, Moses J, Silk KR, Lohr NE, Cohen $\mathrm{R}$, Segal H. Quality of depressive experience in borderline personality disorder and major depression: when depression is not just depression. J Pers Disord. 1992;6(4):392-3.

100 Winnicott DW. Fear of breakdown. Int Rev Psychoanal. 1974;(1):103-7.

101 Caligor E, Kernberg OF, Clarkin JF, Yeomans FE. Psychodynamic therapy for personality pathology: treating self and interpersonal functioning: American Psychiatric Pub; 2018

102 Linehan MM. Cognitive-behavioral treatment of borderline personality disorder. New York, NY, US: Guilford Press; 1993. xvii, 558. (Cognitive-behavioral treatment of borderline personality disorder).

103 Ntshingila N, Poggenpoel M, Myburgh C, Temane A. Experiences of women living with borderline personality disorder. Health SA Gesondheid. 2016;21(1):110-9.

104 Taylor S, Goritsas E. Dimensions of Identity Diffusion. J Pers Disord. 1994 Sep;8(3):22939.

105 Baumeister RF. Identity: Cultural Change and the Struggle for Self. USA: Oxford University Press; 1986.
106 Erikson EH. Identity, youth and crisis. New York: W. W. Norton Company, 1968. Behav Sci. 1969;14(2):154-9.

107 Erikson EH. The Problem of Ego Identity. J Am Psychoanal Assoc. 1956;4(1):56-121.

108 Fonagy P, Bateman AW. Mentalizing and borderline personality disorder. J Ment Health. 2007 Jan; 16(1):83-101.

109 Hoermann S, Clarkin JF, Hull JW, Levy KN The Construct of Effortful Control: An Approach to Borderline Personality Disorder Heterogeneity. PSP. 2005;38(2):82-6.

110 Lenzenweger MF, Clarkin JF, Fertuck EA, Kernberg OF. Executive Neurocognitive Functioning and Neurobehavioral Systems Indicators in Borderline Personality Disorder: A Preliminary Study. J Pers Disord. 2004 Aug;18(5):421-38.

111 Gratz KL, Rosenthal MZ, Tull MT, Lejuez CW, Gunderson JG. An experimental investigation of emotion dysregulation in borderline personality disorder. J Abnorm Child Psychol. 2006;115(4):850-5.

112 Baumeister RF, Shapiro JP, Tice DM. Two kinds of identity crisis. J Pers. 1985;53(3): 407-24.

113 James A, Berelowitz JA, Vereker M. Borderline personality disorder: A study in adolescence. European Child and Adolescent Psychiatry. 1996;5:11-17.

114 Mercer-Lynn KB, Flora DB, Fahlman SA, Eastwood JD. The measurement of boredom: differences between existing self-report scales. Assessment. 2013 Oct;20(5): 585-96.

115 Gunderson JG, Singer MT. Defining borderline patients: an overview. Am J Psychiatry. 1975 Jan;132(1):1-10.

116 Perry JC, Klerman GL. Clinical features of the borderline personality disorder. Am J Psychiatry. 1980 Feb;137(2):165-73.

117 Brown MZ, Comtois KA, Linehan MM. Reasons for suicide attempts and nonsuicidal self-injury in women with borderline personality disorder. J Abnorm Child Psychol. 2002 Feb;111(1):198-202.

118 Chapman AL, Gratz KL, Brown MZ. Solving the puzzle of deliberate self-harm: the experiential avoidance model. Behav Res Ther. 2006 Mar;44(3):371-94.

119 Kamphuis JH, Ruyling SB, Reijntjes AH. Testing the emotion regulation hypothesis among self-injuring females: evidence for differences across mood states. J Nerv Ment Dis. 2007 Nov; 195(11):912-8.

120 Klonsky ED. The functions of deliberate self-injury: A review of the evidence. Clin Psychol Rev. 2007 Mar;27(2):226-39.

121 Klonsky ED. The functions of self-injury in young adults who cut themselves: clarifying the evidence for affect-regulation. Psychiatry Res. 2009 Apr;166(2-3):260-8.

122 Shearer SL. Phenomenology of self-injury among inpatient women with boderline personality disorder. J Nerv Ment Dis. 1994 Sep; 182(9):524-6. 
123 Leibenluft E, Gardner DL, Cowdry RW. The inner experience of the borderline self-mutilator. J Pers Disord. 1987;1(4):317-24.

124 Maggini C. Psychobiology of boredom. CNS Spectr. 2000;5(8):24-7.

125 Gunderson JG. Borderline personality disorder. Arlington (VA): American Psychiatric Publishing; 1984.

126 Parker A. The Meaning of Attempted Suicide to Young Parasuicides: A Repertory Grid Study. Br J Med Psychol. 1981 Oct; 139(4):306-12.

127 Roy A. Self-mutilation. Br J Med Psychol. 1978;51(2):201-3.

128 Nederkoorn C, Vancleef L, Wilkenhöner A, Claes L, Havermans RC. Self-inflicted pain out of boredom. Psychiatry Res. 2016 Mar; 237:127-32.

129 Boschloo L, Vogelzangs N, van den Brink W, Smit JH, Beekman AT, Penninx BW. The role of negative emotionality and impulsivity in depressive/anxiety disorders and alcohol dependence. Psychol Med. 2013 Jun; 43(6):1241-53.

130 Fierro M, Ortegón JJ. Trastorno de personalidad depresivo: El sinsentido de la vida = Depressive Personality Disorder: The Senselessness of Life. Rev Colomb Psiquiatr. 2005 Dec;34(4):581-94.

131 Newell SE, Harries P, Ayers S. Boredom proneness in a psychiatric inpatient population. Int J Soc Psychiatry. 2012 Sep;58(5): 488-95.

132 Zanarini MC, Gunderson JG, Frankenburg FR, Chauncey DL, Glutting JH. The face validity of the DSM-III and DSM-III-R criteria sets for borderline personality disorder. Am J Psychiatry. 1991 Jul;148(7):870-4.

133 Scheel CN, Schneid EM, Tuescher O, Lieb K, Tuschen-Caffier B, Jacob GA. Effects of shame induction in borderline personality disorder. Cognit Ther Res. 2013 Dec;37(6): 1160-8.

134 Hare RD, Neumann CS. The PCL-R assessment of psychopathy. Handbook of psychopathy. 2006. pp. 58-88.

135 Berninger A. Temporal experience, emotions and decision making in psychopathy. Phenomenol Cogn Sci. 2017 Sep;16(4):66177.

136 Levenson MR, Kiehl KA, Fitzpatrick CM Assessing psychopathic attributes in a noninstitutionalized population. J Pers Soc Psychol. 1995;68(1):151-8.

137 Winnicott DW. A Clinical Study of the Effect of a Failure of the Average Expectable Environment on a Child's Mental Functioning. Int J Psychoanal. 1965;46:81-7.
138 Švrakić DM. Emotional features of narcissistic personality disorder. Am J Psychiatry. 1985;142(6):720-4.

139 Wink P, Donahue K. The relation between two types of narcissism and boredom. J Res Pers. 1997 Mar;31(1):136-40.

140 Zondag HJ. Narcissism and boredom revisited: an exploration of correlates of overt and covert narcissism among Dutch university students. Psychol Rep. 2013 Apr;112(2): 563-76.

141 Selby EA, Anestis MD, Bender TW, Joiner TE Jr. An exploration of the emotional cascade model in borderline personality disorder. J Abnorm Psychol. 2009 May;118(2): 375-87.

142 Selby EA, Franklin J, Carson-Wong A, Rizvi SL. Emotional cascades and self-injury: investigating instability of rumination and negative emotion. J Clin Psychol. 2013 Dec; 69(12):1213-27.

143 Selby EA, Anestis MD, Joiner TE. Understanding the relationship between emotional and behavioral dysregulation: emotional cascades. Behav Res Ther. 2008 May;46(5): 593-611.

144 Oldham JM. The alternative DSM-5 model for personality disorders. World Psychiatry. 2015;14(2):234-6.

145 Krueger RF, Markon KE. The Role of the DSM-5 Personality Trait Model in Moving Toward a Quantitative and Empirically Based Approach to Classifying Personality and Psychopathology. Annu Rev Clin Psychol. 2014;10(1):477-501.

146 Barnett LA, Klitzing SW. Boredom in Free Time: Relationships with Personality, Affect, and Motivation for Different Gender, Racial and Ethnic Student Groups. Leis Sci. 2006 May;28(3):223-44.

147 Egan V, McMurran M, Richardson C, Blair M. Criminal cognitions and personality: what does the PICTS really measure? Crim Behav Ment Health. 2000;10(3):170-84.

148 Gordon A, Wilkinson R, McGown A, Jovanoska $\mathrm{S}$. The psychometric properties of the Boredom Proneness Scale: an examination of its validity. Psychol Stud (Mysore). 1997; 42(2-3):85-97.

149 Sulea C, van Beek I, Sarbescu P, Virga D, Schaufeli WB. Engagement, boredom, and burnout among students: basic need satisfaction matters more than personality traits. Learn Individ Differ. 2015 Aug;42:132-8.
150 Miller JD, Lynam DR. Personality and addiction: A critical review of assessment approaches. In: MacKillop J, de Wit H, editors. The Wiley-Blackwell handbook of addiction psychopharmacology. Wiley-Blackwell 2013. pp. 111-33.

151 Smith RP. Boredom: A review. Hum Factors 1981 Jun;23(3):329-40.

152 Culp NA. The relations of two facets of boredom proneness with the major dimensions of personality. Pers Individ. 2006 Oct;41(6): 999-1007.

153 Hunter JA, Abraham EH, Hunter AG, Goldberg LC, Eastwood JD. Personality and boredom proneness in the prediction of creativity and curiosity. Think Skills Creativity. 2016 Dec;22:48-57.

154 Kotov R, Krueger RF, Watson D, Achenbach TM, Althoff RR, Bagby RM, et al. The Hierarchical Taxonomy of Psychopathology (HiTOP): A dimensional alternative to traditional nosologies. J Abnorm Child Psychol. 2017;126(4):454-77.

155 Sharp C, Wright AG, Fowler JC, Frueh BC, Allen JG, Oldham J, et al. The structure of personality pathology: both general (' $\mathrm{g}$ ') and specific ('s') factors? J Abnorm Child Psychol. 2015 May;124(2):387-98.

156 Borsboom D, Cramer AO. Network Analysis: An Integrative Approach to the Structure of Psychopathology. Annu Rev Clin Psychol. 2013;9(1):91-121.

157 Hayes SC, Strosahl KD, Wilson KG. Acceptance and commitment therapy: An experiential approach to behavior change. New York, NY, US: Guilford Press; 1999. xvi, 304.

158 Cameron AY, Palm Reed K, Gaudiano BA. Addressing treatment motivation in borderline personality disorder: rationale for incorporating values-based exercises into dialectical behavior therapy. J Contemp Psychother. 2014 Jun;44(2):109-16.

159 Gunderson JG, Links PS. Borderline personality disorder: A clinical guide. 2nd ed. Arlington (VA): American Psychiatric Publishing, Inc.; 2008.

160 Soler J, Valdepérez A, Feliu-Soler A, Pascual JC, Portella MJ, Martín-Blanco A, et al. Effects of the dialectical behavioral therapymindfulness module on attention in patients with borderline personality disorder. Behav Res Ther. 2012 Feb;50(2):150-7.

161 LePera N. Relationships between boredom proneness, mindfulness, anxiety, depression, and substance use. New School Psychol Bull. 2011 May;8(2):15-25.

162 Petranker R, Eastwood J. Subjective boredom and mindfulness. 2017 May 22; Available from: https://osf.io/5jb4r. 